Journal of Quantitative Spectroscopy \& Radiative Transfer II (III) III-II
Journal of Quantitative Spectroscopy \& Radiative Transfer

www.elsevier.com/locate/jqsrt

\title{
Partition function data and impact on retrieval quality for an $\mathrm{mm} / \mathrm{sub}-\mathrm{mm}$ limb sounder
}

\author{
C.L. Verdes ${ }^{\mathrm{a}, *}$, A. von Engeln ${ }^{\mathrm{a}}$, S.A. Buehler ${ }^{\mathrm{a}}$, A. Perrin ${ }^{\mathrm{b}}$ \\ ${ }^{a}$ Institute of Environmental Physics, University of Bremen, P.O. Box 3304 40, D-28334 Bremen, Germany \\ ${ }^{\mathrm{b}}$ Universite Paris-Sud, F 91405 Orsay, Cedex, France
}

Received 23 September 2003; accepted 17 March 2004

\begin{abstract}
The partition function plays a major role as it mainly governs the dependence of the spectral line strength (or line intensity) on the temperature. A wrong partition function will lead to an incorrect line strength, which will lead to a systematic error in the retrieval. Therefore, a careful investigation of the available partition function data and the sensitivity of the retrieval to this is required. Two partition function data sets, the HITRAN and the JPL, are considered in this paper. In a first step, we investigate the spread of the partition function ratios from the simple approximation values given by theory. We find that the HITRAN partition functions are usually higher than the values quoted by the simple approximation. The JPL partition functions are much closer to the values given by the approximation. Comparing directly the two datasets, with some exceptions, a good agreement is found. Only for 16 molecules (from 66 considered molecules), the deviations in the two data sets are larger than $2 \%$. The retrieval error analysis shows that, for the case of the molecular species with strong signatures, an uncertainty in the partition function is directly translated into a retrieval error of the species in question. However, the uncertainty in the partition function of this species can have a high impact on the quality of weak species retrieval.
\end{abstract}

(c) 2004 Elsevier Ltd. All rights reserved.

Keywords: Remote sensing; Spectroscopy; Partition function data; Retrieval; Error analysis; Atmosphere

\section{Introduction}

Remote sensing observations coupled with increasingly sophisticated computer simulations have led to rapid advances in the understanding of the atmosphere. Millimeter wave remote sensing techniques have improved rapidly over the last few years. These techniques have unique properties, e.g., less sensitivity to cloud contamination compared to infrared and UV-Vis techniques. Since the

\footnotetext{
* Corresponding author. Tel.: +49-4212184657; fax: +49-4212184555.

E-mail address: cverdes@uni-bremen.de (C.L. Verdes).
} 
thermal emission is measured, no external source is needed. The thermal emission at microwave wavelengths depends almost linearly on temperature as opposed to a non-linear relationship in the infrared region. The millimeter wave range contains, among many others, spectral features of ozone, water vapor, nitrous oxide, chlorine monoxide, and bromine monoxide, all of which are species of major importance for ozone chemistry or for the greenhouse effect. The quantity measured by the satellites contains implicitly information on the atmospheric state (e.g., molecular species volume mixing ratio profiles, temperature profile). An accurate retrieval of the quantities of interest requires accurate knowledge about the measurement and retrieval system. This includes also accurate knowledge of the spectroscopic database, such as the line strength. An important role plays the partition function data as this is the quantity needed to convert the line strength given at a reference temperature in the spectroscopic database, to atmospheric temperatures. Thus, a wrong partition function will lead to an incorrect line strength, which will lead to a systematic retrieval error.

\section{Basic equations}

\subsection{Radiative transfer equation}

The extraction of the information from a satellite measurement requires knowledge of the radiative transfer in the atmosphere. The radiative transfer equation, introduced by Chandrasekhar [1], describes the way in which the intensity is affected by extinction and emission of radiation. For the case of a non-scattering atmosphere (clear sky), which is mainly fulfilled in the microwave spectral range, for an arbitrary slant path, the intensity $I$ (defined as the power of radiation per unit area, per unit solid angle, and per unit frequency interval), at frequency $v$, received by an instrument at position $l=0$, is given by

$$
I(v)=I_{\infty}(v) \zeta_{v}(\infty)+\int_{0}^{\infty} k_{v}(l) B_{v}(T(l)) \zeta_{v}(l) \mathrm{d} l,
$$

where $k_{v}$ is the total absorption coefficient, $\zeta_{v}$ is the transmittance, $B_{v}$ is the Planck function (which is derived under thermodynamic equilibrium condition), and $I_{\infty}$ is the intensity at the limit of the atmosphere, which can be cosmic background radiation or emission from the ground. For a more thorough description of these terms, please refer to [2,3].

In order to solve Eq. (1) the absorption coefficient $k_{v}$ has to be calculated. The main part of the calculation is a summation of the contribution of the individual lines, henceforth called line absorption coefficient, but also non-resonant terms of water vapor, oxygen and nitrogen, the so-called continua absorption, have to be considered. The subject of continua is outside of the purpose of this paper. Details about the continua can be found in, e.g., [4-8].

For a mixture of gases, the line absorption coefficient is obtained by summing over all species:

$$
k_{v}=\sum_{s} k_{v}^{s},
$$

where $k_{v}^{s}$ is the absorption coefficient for species $s$. 
Three quantities define the absorption coefficient of a molecular species, $k_{v}^{s}$ : the strength of the line $S$, the line shape $f\left(v, v_{0}\right)$ describing the distribution in frequency, and its position given by the center frequency $v_{0}$. In general, the species absorption coefficient is obtained by summing over the contributions of all possible transitions:

$$
k_{v}^{s}=n \sum_{i, j} S_{i j}(T) f\left(v, v_{0}\right)
$$

where $n$, which is proportional to the volume mixing ratio VMR, is the number of molecules of the species per unit volume, and $i$ and $j$ are indices of the upper and the lower energy levels of a possible transition.

The center frequency, $v_{0}$, of one transition is related to the energy levels of the transition by: $v_{0}=\left(E_{i}-E_{j}\right) / h$ where $E_{i}$ and $E_{j}$ are the upper and lower energy level, respectively, and $h$ is Planck's constant.

Here, the quantity of interest is the line strength, $S_{i j}$. The line strength depends both on the properties of a single molecule and the populations of the molecules in the upper and lower energy levels which in turn depends on the temperature of their environment. If local thermodynamic equilibrium is assumed then the state occupations in the molecule can be assumed to follow a Boltzmann distribution, thus the line strength can be written as [9]

$$
S_{i j}(T)=\frac{8 \pi^{3} v_{0}\left|\mu_{i j}\right|^{2} g_{j} g_{i}}{3 h c Q(T)}\left(\mathrm{e}^{-E_{j} / k T}-\mathrm{e}^{-E_{i} / k T}\right),
$$

where $g_{j}$ and $g_{i}$ are the degeneracies ${ }^{1}$ of the lower and upper energy levels, (the energy levels involved in the transition), respectively $E_{j}$ and $E_{i}$ are the energies of those levels, $\left|\mu_{i j}\right|$ is the magnitude of the dipole moment of the molecule, and $Q$ is a factorizing term called the partition function.

The partition function $Q$ has an important role since it governs to a large extent the temperature dependence of the line strength. It describes the internal energy distribution of the molecule between nuclear spin, rotational, vibrational, and electronic states. Since the energy levels are well separated, the partition function can be expressed as

$$
Q(T)=Q_{\text {elec }}(T) Q_{\text {vib }}(T) Q_{\text {rot }}(T),
$$

where the nuclear spin partition function is included in the rotational part, $Q_{\text {rot }}$. With a few exceptions, $Q_{\text {elec }}(T)$ can be approximated as unity for temperatures found in the atmosphere. One exception is $\mathrm{ClO}$, which has an electronic state corresponding to a temperature of $458 \mathrm{~K}$.

The vibrational partition function $Q_{\mathrm{vib}}(T)$ is calculated by modeling the molecule as a harmonic oscillator:

$$
Q_{\mathrm{vib}}(T)=\prod_{i}\left[1-\exp \left(-h \omega_{i} / k T\right)\right]^{-d_{i}},
$$

where $\omega_{i}$ is the fundamental frequency of mode $i$ and $d_{i}$ is the degeneracy, which is normally 1 . One exception is the bending mode of $\mathrm{N}_{2} \mathrm{O}$ which has $d=2$.

\footnotetext{
${ }^{1}$ Degeneracy is the number of levels of equal energy in which a molecule may lie.
} 


\section{ARTICLE IN PRESS}

The temperature dependence of the rotational partition function can be approximated by (hereafter called the simple approximation)

$$
Q_{\text {rot }}(T)=Q_{\text {rot }}\left(T_{0}\right)\left(T / T_{0}\right)^{n}, \quad \text { i.e., } \quad R_{\text {simple }}(T)=\frac{Q_{\text {rot }}\left(T_{0}\right)}{Q_{\text {rot }}(T)}=\left(\frac{T_{0}}{T}\right)^{n},
$$

where the exponent factor $n=1$ for linear molecules (all diatomic molecules and some other molecules such as $\mathrm{CO}_{2}$ and $\mathrm{N}_{2} \mathrm{O}$ ), and $n=\frac{3}{2}$ for the asymmetric molecules, such as $\mathrm{O}_{3}, \mathrm{H}_{2} \mathrm{O}$, and $\mathrm{NH}_{3}$.

In practice, $Q(T)$ is derived from tabulated values by interpolation. The line strength at a reference temperature $T_{0}, S\left(T_{0}\right)$, is obtained from a spectroscopic database. The line strength at other temperature is obtained by an interpolation relation as

$$
S(T)=S\left(T_{0}\right) \frac{Q\left(T_{0}\right)}{Q(T)} .
$$

Using Eq. (5), one can write

$$
R(T)=\frac{Q\left(T_{0}\right)}{Q(T)}=\frac{Q_{\text {elec }}\left(T_{0}\right) Q_{\mathrm{vib}}\left(T_{0}\right) Q_{\mathrm{rot}}\left(T_{0}\right)}{Q_{\mathrm{elec}}(T) Q_{\mathrm{vib}}(T) Q_{\mathrm{rot}}(T)} .
$$

\subsection{Inversion theory and basic error analysis}

Inversions of atmospheric measurements can be described in the context of the optimal estimation method (OEM) formalism described by Rodgers [10,11]. This section briefly outlines the essential details of the OEM formalism and basic error analysis. For a detailed explanation please refer to $[3,10,11]$.

The OEM formalism starts with a general time-independent computer model [12], F, modeling the radiative transfer through the atmosphere and the detecting instrument. Mathematically, this can be described as

$$
y=\mathbf{F}(x, b)+\varepsilon y
$$

where y, called measurement vector, is the data obtained from the measurement (derived from $I$ of Eq. (1)), $x$ is the state vector which contains all the parameters of interest that are intended to be retrieved from the data, e.g., molecular species volume mixing ratios (VMR) and temperature profile, $b$ is the model parameter vector containing all the parameters treated as constant during the retrieval process (e.g., the spectroscopic data, partition function data, instrumental parameters, etc.), and $\varepsilon_{y}$ is the measurement noise (having a covariance matrix $S_{\varepsilon}$ ) which is added to the signal from the atmosphere.

An inverse (or retrieval) method I has to be applied to the measurement vector in order to retrieve an optimal estimate $\hat{x}$ of the state vector $x$, i.e., $\hat{x}=\mathbf{I}(y)$. Inversion problems of satellite data are often ill-posed and therefore need a regularization. To obtain stable solutions in our retrieval procedure, we use a priori information about the mean atmospheric condition ( $\mathrm{x}_{\mathrm{a}}$, with the a priori covariance matrix $S_{a}$ ). Additionally, one can determine the impact of the constant model parameters on the retrieval by assuming that only an a priori $b_{a}$, representing the best knowledge of the model parameters, with a priori covariance matrix $\mathrm{S}_{\mathrm{b}}$ is given. 
In order to perform a retrieval and a basic error analysis, the Jacobian of the measurement with respect to $x, K_{x}=\partial \mathbf{F}\left(x, b_{a}\right) /\left.\partial x\right|_{x_{a}}$, and with respect to $b, K_{b}=\partial \mathbf{F}\left(x_{a}, b\right) /\left.\partial b\right|_{b_{a}}$, and the Jacobian of the inverse (retrieval) model with respect to the measurement, $D_{y}=\partial \mathbf{I}(y) / \partial y$, the so-called contribution function matrix, have to be calculated. The calculation of these Jacobians requires a linearization of the forward and retrieval model.

From the OEM theory the error in the retrieval, which represents the deviation of the retrieved state vector $\hat{x}$ from the true state vector $x$, can be expressed as (for more details please refer to [3])

$$
\Delta x=\hat{x}-x=\underbrace{(A-I)\left(x-x_{a}\right)}_{(1)}+\underbrace{D_{y} \varepsilon_{y}}_{(2)}+\underbrace{D_{y} K_{b}\left(b-b_{a}\right)}_{(3)}
$$

with I the identity matrix, and $A$, resulting from the multiplication of $K_{x}$ and $D_{y}$, the so-called averaging kernel matrix. The averaging kernel matrix gives an estimate of the vertical resolution of the retrieval. In the ideal case it corresponds to the identity matrix.

Three different sources of errors can be identified in Eq. (11):

(1) The smoothing error (with the covariance matrix $\left.N=(A-I) S_{a}(A-I)^{T}\right)$ is related to the need of a priori information. This extra or additional information quantifies our expectation of the solution independent of the actual data.

(2) The measurement error (with the covariance matrix $M=D_{y} S_{\varepsilon} D_{y}^{T}$ ) is due to the noise which appears in the measurement.

(3) The model parameter error (with the covariance matrix $\left.P=\left(D_{y} K_{b}\right) S_{b}\left(D_{y} K_{b}\right)^{T}\right)$ is caused by uncertainties in model parameter, such as spectroscopic or instrumental parameters.

Within this paper, we refer to the retrieval precision matrix, $S$, which means the sum of the smoothing and measurement error covariance matrices $(S=N+M)$.

The model parameter vector b plays an important role in the formalism presented above, and it is usually treated as a known constant in the forward and retrieval model. If one knows the statistics of the model parameters $b$, that means the covariance matrix $S_{b}$ is known, then the model error covariance matrix $\mathrm{P}$, describing the resulting error on the retrieval, can be easily calculated (see the relation quoted above). If there is no linear relationship between changes in $b$ and changes in the measurement vector, it is not appropriate to use the linearized form of the forward model to investigate such errors. Our approach is therefore to linearize the inverse (retrieval) model only, that is to use the contribution function matrix, Dy, and to employ the full forward model. By neglecting measurement noise and setting the a priori values of $x_{a}$ to the true values already, the error in the retrieved state vector is exclusively determined by the uncertainties in the model parameters, $\Delta \mathrm{b}$. Doing this, Eq. (11) can be rewritten as

$$
\Delta x=D_{y}\left[\mathbf{F}\left(x_{a}, b_{a}+\Delta b\right)-\mathbf{F}\left(x_{a}, b_{a}\right)\right]=D_{y} \Delta y .
$$

Once the contribution function matrix $D_{y}$ at $y=\mathbf{F}\left(x_{a}, b_{a}\right)$ has been calculated, it can be used for the entire investigation of statistical and systematic parameter errors, which makes this linear mapping method computationally efficient. An additional advantage of the linear mapping method is that $\Delta \mathrm{b}$ can have any statistical distribution and is therefore not restricted to Gaussian distributions. Eq. (12) is the one which has been used in this paper. 


\section{Partition function data}

The information on the partition function are usually taken either from the HITRAN [13,14] or JPL [15-17] database.

The HITRAN database provides total internal partition functions for 105 species [13]. These include the data for all molecular species found in the 2000 HITRAN database [18], and, in addition, data for 13 other isotopomers/isotopologues of ozone and carbon dioxide. The calculations address the corrections suggested by Goldman et al. [14]. The calculations of the partition functions consider the temperature range $70-3000 \mathrm{~K}$, in steps of $25 \mathrm{~K}$ to be applicable to a variety of remote sensing needs. The partition functions for any temperatures other than the ones at which the data are provided, are calculated by a Lagrange 4-point interpolation [13]. More information on the HITRAN database can be found at http://www.hitran.com/.

The JPL database provides only the rotational-spin partition function for temperatures at 300, 225, $150,75,37.5,18.75$, and $9.375 \mathrm{~K}$, but for a larger number of molecules (166 molecules). Values for intermediate temperatures have to be obtained by interpolation. They are calculated according to the scheme given in the JPL database, i.e., following Eq. (7). No vibrational partition function is included, the stated partition function is calculated for the total concentration of the vibrationalelectronic state of the molecule. Exceptions have been made for some species, e.g., $\mathrm{O}_{3}$ and $\mathrm{H}_{2} \mathrm{O}$, where the vibrational partition function is also included. As mentioned, for most molecular species the electronic states can be neglected. One exception is $\mathrm{ClO}$ but in this case the influence of the electronic states is considered in the JPL database. Therefore, some corrections of the partition function values quoted in JPL have to be made. The vibrational partition function $Q_{\mathrm{vib}}(T)$ is calculated by modeling the molecule as a harmonic oscillator using Eq. (6). In this paper, the information on the vibrational modes are taken, for most of molecular species, from [19]; the data, for some molecular species, not available in [19] are taken either from [20,21] or [22]. Vibrational corrections for the minor isotopes is performed with the vibrational modes of major isotopes. This is a common approximation in the microwave range. More information on the JPL database can be found at http://spec.jpl.nasa.gov.

In order to see the level of agreement between different sources of partition function data, an intercomparison has been carried out. The comparison is focusing to the ratio of the partition function, $R(T)$ defined by Eq. (9), as this is the necessary quantity to convert the line strength stated at a reference temperature in the spectroscopic data to others temperatures (Eq. (8)). A reference temperature of $300 \mathrm{~K}$, the same one at which the line strength is quoted in the JPL database, has been taken. The intercomparison is performed at two temperatures ( 150 and $225 \mathrm{~K}$ ), common to both database.

In a first step, we investigated the deviation of the partition functions quoted in the two datasets from the values given by the simple approximation $\left(R_{\text {simple }}(T)\right)$, calculated by using Eq. (7). For a reference temperature $T_{0}=300 \mathrm{~K}$, and $T=[150 \mathrm{~K}, 225 \mathrm{~K}]$, we have $R_{\text {simple }}(150 \mathrm{~K})=2.00$ and $R_{\text {simple }}(225 \mathrm{~K})=1.33$ for linear molecules, and $R_{\text {simple }}(150 \mathrm{~K})=1.41$ and $R_{\text {simple }}(225 \mathrm{~K})=1.15$ for non-linear molecules. In order to have a better overview, the set of species have been separated in four different groups: (1) linear molecules (such as $\mathrm{CO}, \mathrm{CO}_{2}$ ), (2) non-linear molecules with three atoms (such as $\mathrm{O}_{3}$ or $\mathrm{H}_{2} \mathrm{O}$ ), (3) non-linear molecules with four atoms (such as $\mathrm{H}_{2} \mathrm{O}_{2}, \mathrm{NH}_{3}$ ), and (4) non-linear molecules with five and more atoms (such as $\mathrm{CH}_{3} \mathrm{Cl}, \mathrm{HNO}_{3}, \mathrm{ClONO}_{2}$ ). The spread of

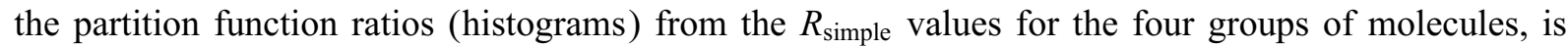
shown in Fig. 1 (for the HITRAN data set) and Fig. 2 (for the JPL data set). The middle light line 

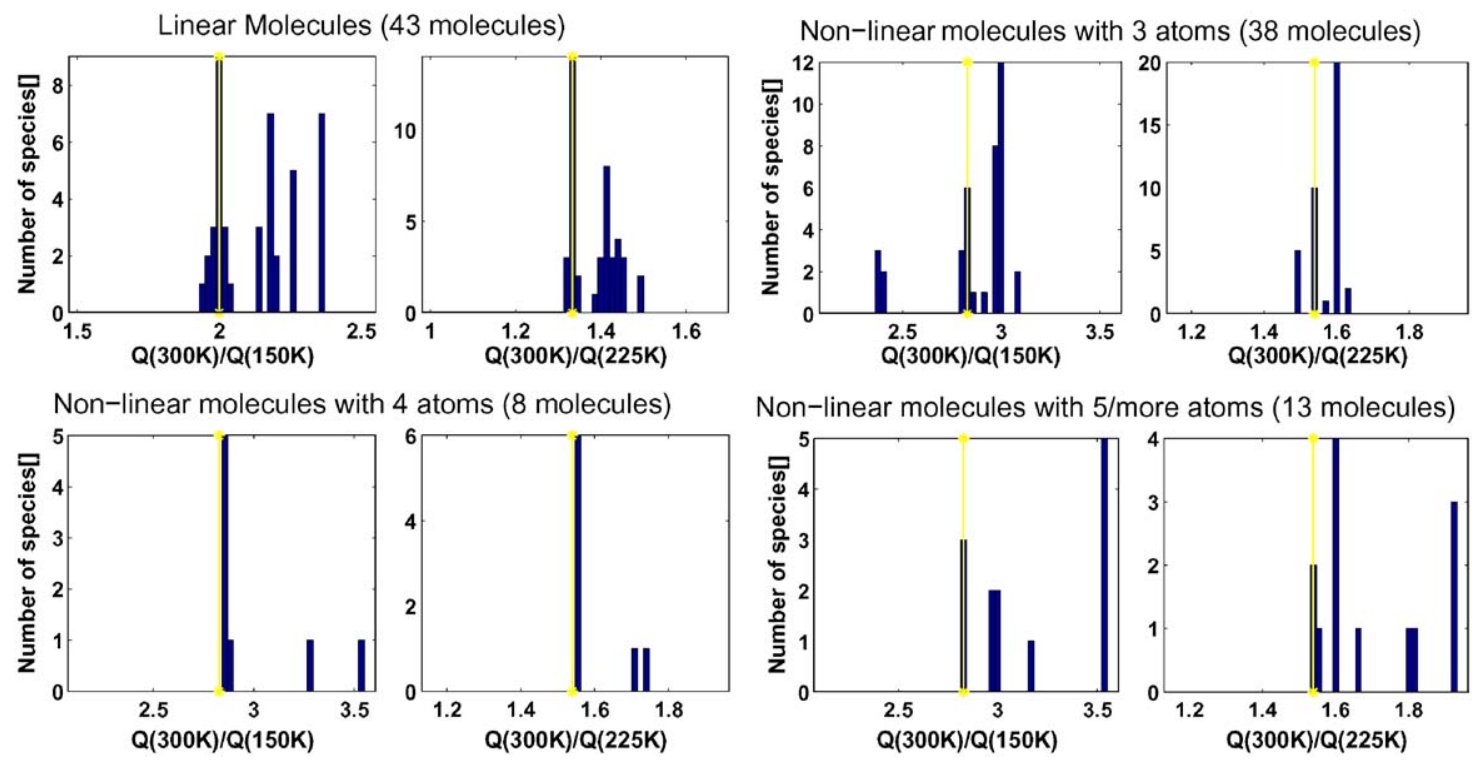

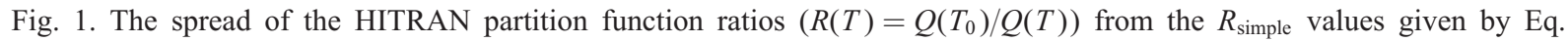
(7), for two temperatures $(150$ and $225 \mathrm{~K})$, and a reference temperature $T_{0}=300 \mathrm{~K}$.

from each figure marks the corresponding $R_{\text {simple }}$ value. To have a better clarity, only the molecules whose partition function ratios deviate less than $25 \%$ from $R_{\text {simple }}$ are considered; the molecules with a partition function ratio far away from the corresponding $R_{\text {simple }}$ values are not included in the histograms. The total number of molecules found to have deviations from the $R_{\text {simple }}$ values in the considered range of $\pm 25 \%$ is given in the top of each plot. More detailed results are displayed in Table 1 (for HITRAN), and Table 2 (for JPL). Listed is the relative deviation (in \%) with respect to the corresponding $R_{\text {simple }}$ value, for a variety of molecular species, and for different isotopes. The notation for the molecular species isotopes generally follows the HITRAN convention, e.g., for the main $\mathrm{H}_{2} \mathrm{O}$ isotope we have $\mathrm{H}_{2} \mathrm{O}-161$, thus, the last digit of the sum of the neutrons and protons of the individual atoms is taken. Nevertheless, molecules like $\mathrm{H}_{2} \mathrm{CO}$ have only three digits in HITRAN, since only one number for the two $\mathrm{H}$ atoms (thus, $\mathrm{H}_{2} \mathrm{CO}-126$ from HITRAN becomes $\mathrm{H}_{2} \mathrm{CO}-1126$ in our notation).

For most molecules, for the investigated temperatures, the HITRAN partition function ratios are found to be higher than the $R_{\text {simple }}$ value. That is already understood as $R_{\text {simple }}$ refers only to the rotation partition function, while the HITRAN data set gives the total partition function. We suspect that these differences are mainly due to the vibrational partition function. From Eq. (6) one sees that the vibrational partition function $Q_{\text {vib }}(T)$ is increasing with increasing temperature. Thus, since the reference temperature, $T_{0}$, is higher compared to the investigated ones $(150$ and $225 \mathrm{~K}$, respectively), it means that the ratio $Q_{\mathrm{vib}}\left(T_{0}\right) / Q_{\mathrm{vib}}(T)$ is greater than unity, explaining the larger values for HITRAN compared to the $R_{\text {simple }}$ values. For some molecules, the deviation is somewhat larger, e.g., for the diatomic molecules $\mathrm{ClO}$ and $\mathrm{NO}(18 \%$ deviation at $150 \mathrm{~K}$, and about $9 \%$ at $225 \mathrm{~K}$ ), and $\mathrm{OH}(9 \%$ at $150 \mathrm{~K}$ and $4 \%$ at $225 \mathrm{~K})$, explained by the fact that these molecules have a high vibrational mode which leads to the large deviation of the total partition function from the $R_{\text {simple }}$ 

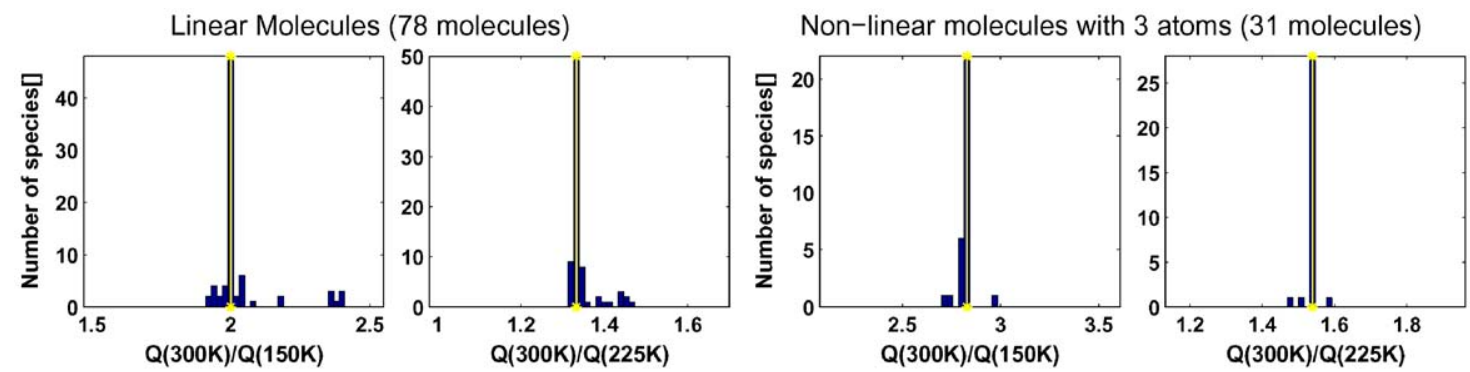

Non-linear molecules with 4 atoms (22 molecules)

Non-linear molecules with 5/more atoms (30 molecules)
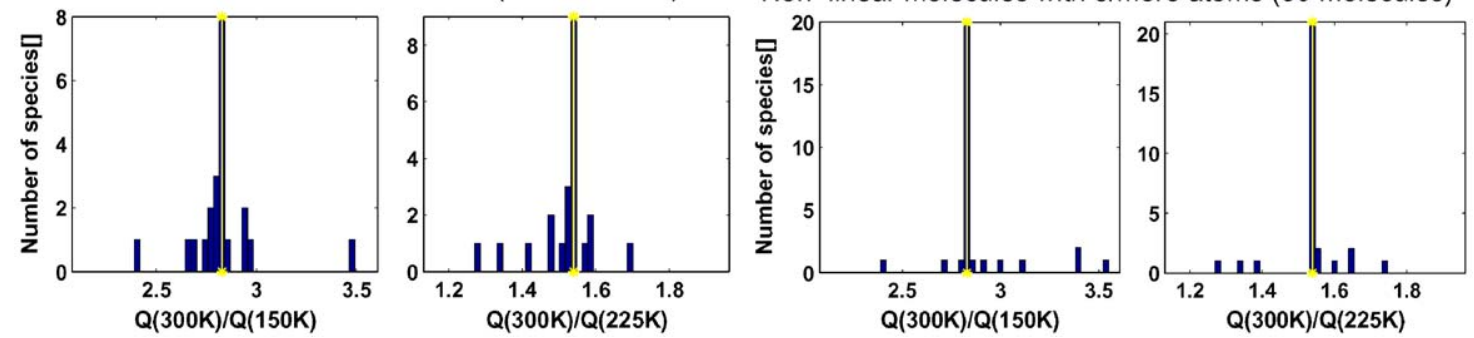

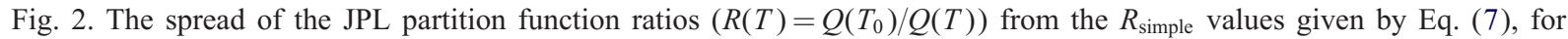
two temperatures $(150$ and $225 \mathrm{~K})$, and a reference temperature $T_{0}=300 \mathrm{~K}$. No vibrational correction to the JPL partition function is applied.

value, but also for some linear molecules with three or more atoms, e.g., $\mathrm{C}_{2} \mathrm{H}_{2}(18 \%$ at $150 \mathrm{~K})$ and for $\mathrm{N}_{2} \mathrm{O}(13 \%)$. The same applies to the non-linear molecules (Fig. 1). The highest deviation is found for $\mathrm{SF}_{6}(188 \%$ at $150 \mathrm{~K}), \mathrm{C} \mathrm{ONO}_{2}(159 \%$ at $150 \mathrm{~K})$, but also for other molecules (see Table 1 ). Only for a few molecules are the investigated partition function ratios lower than the $R_{\text {simple }}$ values. This is the case for the OCS isotopes, for which the ratio at $150 \mathrm{~K}$ is $15 \%$ lower than the

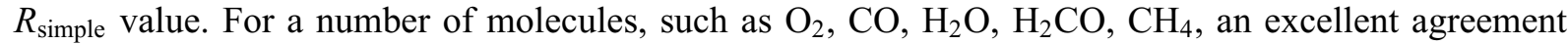
is found.

Similar results are shown in Fig. 2 for the JPL partition function ratios. The partition function ratios for most molecules are in an excellent agreement with the values given by the simple approximation

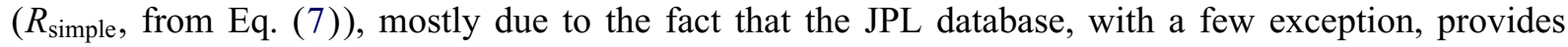
only the rotational partition functions for which Eq. (7) is valid. Thus, the JPL partition function ratios for 49 (out of 78) linear molecules, 25 (out of 31) non-linear molecules with three atoms, 9 (out of 22) non-linear molecules with four atoms, 20 (out of 30) non-linear molecules with five

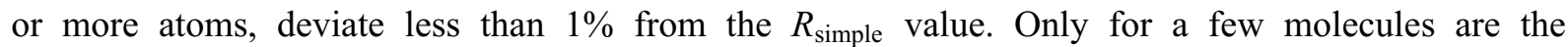
deviations from $R_{\text {simple }}$ values somewhat larger. This is the case, e.g., for the linear molecules with two atoms, such as NS, NO (for this molecule the HITRAN partition function ratio has been found to have also a high deviation), and $\mathrm{ClO}$ (more than $15 \%$ at $150 \mathrm{~K}$ and less at $225 \mathrm{~K}$, due to the electronic partition function which, for this specific molecule, is considered in the JPL data set), for the non-linear molecules with three atoms $\mathrm{O}_{3}(5 \%$ at $150 \mathrm{~K}$, due to vibrational correction included in $\mathrm{JPL})$ and $\mathrm{OClO}(4 \%$ at $150 \mathrm{~K})$, and other non-linear molecules with four or more atoms, such as $\mathrm{CH}_{2} \mathrm{O}_{2}, \mathrm{H}_{3} \mathrm{CN}, \mathrm{H}_{2} \mathrm{O}_{2}$, and $\mathrm{ClONO}_{2}$ (see Table 2). 


\section{ARTICLE IN PRESS}

C.L. Verdes et al. / Journal of Quantitative Spectroscopy \& Radiative Transfer II (III) II-III

9

Table 1

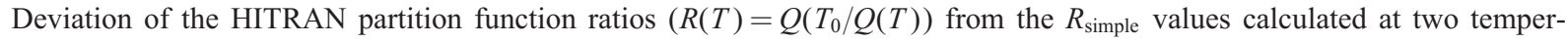
atures, 150 and $225 \mathrm{~K}$, and for a reference temperature of $300 \mathrm{~K}$.

\begin{tabular}{|c|c|c|c|c|c|}
\hline Molecule & $\Delta_{150 \mathrm{~K}}(\%)$ & $\Delta_{225 \mathrm{~K}}(\%)$ & Molecule & $\Delta_{150 \mathrm{~K}}(\%)$ & $\Delta_{225 \mathrm{~K}}(\%)$ \\
\hline \multicolumn{6}{|c|}{ Linear molecules } \\
\hline $\mathrm{ClO}-76$ & 18.4 & 9.2 & HCN-134 & 6.7 & 4.8 \\
\hline $\mathrm{ClO}-56$ & 18.4 & 9.2 & $\mathrm{HCN}-124$ & 6.6 & 4.7 \\
\hline NO-48 & 18.3 & 6.6 & HF-19 & -3.2 & -1.0 \\
\hline NO-56 & 18.3 & 6.6 & $\mathrm{OH}-81$ & 1.6 & 1.4 \\
\hline $\mathrm{NO}-46$ & 18.3 & 6.6 & $\mathrm{HCl}-15$ & -1.6 & -0.5 \\
\hline $\mathrm{C} 2 \mathrm{H} 2-1231$ & 17.7 & 11.8 & $\mathrm{HCl}-17$ & -1.6 & -0.5 \\
\hline C2H2-1221 & 17.7 & 11.8 & OH-61 & 1.5 & 1.4 \\
\hline $\mathrm{N} 2 \mathrm{O}-456$ & 13.4 & 8.6 & $\mathrm{HBr}-19$ & -1.2 & -0.4 \\
\hline N2O-448 & 12.9 & 8.3 & $\mathrm{HBr}-11$ & -1.2 & -0.4 \\
\hline $\mathrm{N} 2 \mathrm{O}-546$ & 12.8 & 8.3 & HI-17 & -0.9 & -0.3 \\
\hline N2O-447 & 12.8 & 8.2 & $\mathrm{O} 2-67$ & 0.8 & 0.3 \\
\hline $\mathrm{N} 2 \mathrm{O}-446$ & 12.6 & 8.1 & O2-68 & 0.8 & 0.3 \\
\hline $\mathrm{CO} 2-638$ & 9.6 & 6.5 & $\mathrm{NO}+-46$ & -0.3 & -0.1 \\
\hline $\mathrm{CO} 2-637$ & 9.5 & 6.4 & O2-66 & -0.3 & -0.0 \\
\hline $\mathrm{CO} 2-636$ & 9.4 & 6.3 & N2-44 & -0.2 & -0.0 \\
\hline $\mathrm{CO} 2-828$ & 9.0 & 6.1 & $\mathrm{CO}-26$ & -0.2 & -0.0 \\
\hline $\mathrm{OH}-62$ & 9.0 & 3.9 & $\mathrm{CO}-27$ & -0.2 & -0.0 \\
\hline $\mathrm{CO} 2-728$ & 8.9 & 6.0 & $\mathrm{CO}-28$ & -0.2 & -0.0 \\
\hline $\mathrm{CO} 2-727$ & 8.8 & 6.0 & $\mathrm{CO}-36$ & -0.2 & -0.0 \\
\hline $\mathrm{CO} 2-628$ & 8.8 & 6.0 & $\mathrm{CO}-37$ & -0.2 & -0.0 \\
\hline $\mathrm{CO} 2-627$ & 8.7 & 5.9 & $\mathrm{CO}-38$ & -0.2 & -0.0 \\
\hline $\mathrm{HCN}-125$ & 6.9 & 4.8 & & & \\
\hline \multicolumn{6}{|c|}{ Non-linear molecules with three atoms } \\
\hline OCS-622 & -15.7 & -3.1 & O3-786 & 5.5 & 3.9 \\
\hline OCS-623 & -15.6 & -3.1 & O3-767 & 5.3 & 3.8 \\
\hline OCS-624 & -15.6 & -3.0 & O3-668 & 5.3 & 3.8 \\
\hline OCS-822 & -15.0 & -2.7 & O3-776 & 5.3 & 3.8 \\
\hline OCS-632 & -14.7 & -2.5 & O3-686 & 5.3 & 3.8 \\
\hline SO2-626 & 9.1 & 5.7 & O3-667 & 5.1 & 3.7 \\
\hline SO2-646 & 9.0 & 5.7 & O3-676 & 5.1 & 3.7 \\
\hline O3-888 & 6.1 & 4.3 & O3-666 & 4.9 & 3.6 \\
\hline O3-878 & 5.9 & 4.2 & NO2-646 & 3.1 & 2.2 \\
\hline O3-887 & 5.9 & 4.2 & H2O-161 & -1.1 & -0.3 \\
\hline HOBr-161 & 5.8 & 3.9 & H2O-162 & 0.7 & 0.3 \\
\hline HOBr-169 & 5.8 & 3.9 & H2O-172 & -0.6 & -0.1 \\
\hline O3-868 & 5.7 & 4.0 & H2O-182 & -0.6 & -0.1 \\
\hline O3-778 & 5.7 & 4.0 & HO2-166 & 0.5 & 0.5 \\
\hline O3-787 & 5.7 & 4.1 & H2S-121 & -0.4 & 0.0 \\
\hline O3-886 & 5.7 & 4.0 & H2S-131 & -0.4 & 0.0 \\
\hline O3-768 & 5.5 & 3.9 & H2S-141 & -0.4 & 0.0 \\
\hline
\end{tabular}


Table 1 (continued)

\begin{tabular}{|c|c|c|c|c|c|}
\hline Molecule & $\Delta_{150 \mathrm{~K}}(\%)$ & $\Delta_{225 \mathrm{~K}}(\%)$ & Molecule & $\Delta_{150 \mathrm{~K}}(\%)$ & $\Delta_{225 \mathrm{~K}}(\%)$ \\
\hline O3-777 & 5.5 & 3.9 & H2O-181 & -0.1 & 0.0 \\
\hline O3-678 & 5.5 & 3.9 & H2O-171 & 0.1 & 0.1 \\
\hline \multicolumn{6}{|c|}{ Non-linear molecules with four atoms } \\
\hline $\mathrm{H} 2 \mathrm{O} 2-1661$ & 26.9 & 13.1 & $\mathrm{H} 2 \mathrm{CO}-1136$ & 0.7 & 0.6 \\
\hline COF2-269 & 16.1 & 10.7 & $\mathrm{H} 2 \mathrm{CO}-1126$ & 0.7 & 0.6 \\
\hline PH3-1111 & 1.5 & 1.4 & NH3-5111 & 0.6 & 0.8 \\
\hline $\mathrm{H} 2 \mathrm{CO}-1128$ & 0.7 & 0.6 & NH3-4111 & 0.6 & 0.8 \\
\hline \multicolumn{6}{|c|}{ Non-linear molecules with five atoms } \\
\hline SF6-29 & 187.7 & 89.3 & $\mathrm{C} 2 \mathrm{H} 4-221$ & 5.6 & 4.4 \\
\hline ClONO2-7646 & 158.7 & 64.1 & CH3Cl-217 & 4.9 & 3.7 \\
\hline ClONO2-5646 & 158.7 & 64.1 & CH3Cl-215 & 4.9 & 3.7 \\
\hline C2H6-1221 & 30.9 & 17.1 & CH4-212 & 0.3 & 0.5 \\
\hline HNO3-146 & 29.1 & 18.1 & CH4-311 & 0.2 & 0.5 \\
\hline НСОOH-126 & 12.0 & 8.2 & CH4-211 & 0.2 & 0.5 \\
\hline C2H4-231 & 5.7 & 4.4 & & & \\
\hline
\end{tabular}

The notation for the molecular species isotopes generally follows the HITRAN convention, i.e., each digit represents the last digit of the sum of the neutrons and protons of the individual atoms.

In a second step, an intercomparison between the HITRAN and JPL partition function has been carried out. The intercomparison looks at the ratio $R(T)$ for temperatures of 150,225 , and $300 \mathrm{~K}$ (set as reference temperature), chosen as both database provide the data at these temperatures. Only the species common to the two data sets are considered (66 molecules). In order to have consistency, a vibrational correction of the JPL partition function is applied in advance. The relative deviations of the corrected JPL partition function ratios from the HITRAN ones are displayed in Table 3. Generally, the partition function data sets are found to be in good agreement. With a few exception, the relative deviation of the corrected JPL partition function ratios from the HITRAN partition function ratios are found to be smaller or close to $1 \%$ (50 out of 66 molecules). The JPL partition function ratios present a remarkably larger deviation from the HITRAN ones only for $\mathrm{ClONO}_{2}(23 \%$ at $150 \mathrm{~K})$; this molecule has been found to have also the largest deviation from the calculated $R_{\text {simple values given }}$ by Eq. (7). Another deviations, however much smaller, are found for $\mathrm{HCl}(2.3 \%), \mathrm{HOBr}(2.2 \%)$, and $\mathrm{HBr}\left(1.9 \%\right.$ ), and for $\mathrm{CH}_{4}$ only at $225 \mathrm{~K}$ (a non-linearity) (see Table 3). For the $\mathrm{H}_{2} \mathrm{O}$ isotopes the JPL ratios presents a deviation of about $1 \%$ from the HITRAN ratios at low temperatures. The investigated JPL ratios are generally found to be lower than the HITRAN ones. The only visible exception is $\mathrm{ClO}$, for which the JPL investigated ratios are with $1.1 \%$ higher than the HITRAN ratios. The best agreement is obtained for more than 20 molecules, e.g., for $\mathrm{O}_{3}, \mathrm{SO}_{2}, \mathrm{HOCl}, \mathrm{OH}$, $\mathrm{O}_{2}, \mathrm{CH}_{3} \mathrm{Cl}$, CO, and $\mathrm{N}_{2} \mathrm{O}$ (see Table 3). The data for the major isotopes agree generally better than the minor isotopes. This is caused by the used approximation for the vibrational correction of the minor isotopes.

Some additional results for a number of species of major importance for remote sensing are displayed in Fig. 3. 


\section{ARTICLE IN PRIESS}

C.L. Verdes et al. / Journal of Quantitative Spectroscopy \& Radiative Transfer II (II) II- II

Table 2

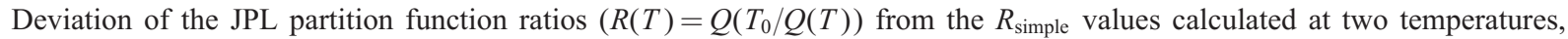
150 and $225 \mathrm{~K}$, and for a reference temperature of $300 \mathrm{~K}$.

\begin{tabular}{|c|c|c|c|c|c|}
\hline Molecule & $\Delta_{150 \mathrm{~K}}(\%)$ & $\Delta_{225 \mathrm{~K}}(\%)$ & Molecule & $\Delta_{150 \text { К }}(\%)$ & $\Delta_{225 \mathrm{~K}}$ \\
\hline \multicolumn{6}{|c|}{ Linear molecules } \\
\hline NS-42 & 20.2 & 8.3 & HNC-152 & -0.2 & -0.1 \\
\hline NS-44 & 20.2 & 8.3 & O2-66 & -0.2 & -0.1 \\
\hline PO-16 & 19.7 & 8.2 & HCN-224 & -0.2 & -0.1 \\
\hline PS-12 & 19.3 & 9.8 & HCN-125 & -0.2 & -0.1 \\
\hline NO-46 & 17.8 & 6.5 & $\mathrm{HCN}-124$ & -0.2 & -0.1 \\
\hline $\mathrm{ClO}-76$ & 17.6 & 8.9 & $\mathrm{C} 2 \mathrm{H}-221$ & -0.2 & -0.1 \\
\hline $\mathrm{ClO}-56$ & 17.6 & 8.9 & HNC-142 & -0.2 & -0.1 \\
\hline OH-62 & 9.0 & 3.9 & HNC-242 & -0.2 & -0.1 \\
\hline SH-22 & 8.5 & 5.2 & $\mathrm{C} 3 \mathrm{O}-2226$ & -0.2 & -0.1 \\
\hline SH-21 & 4.3 & 3.8 & CS-24 & -0.2 & -0.1 \\
\hline HCl-15 & -3.8 & -1.3 & CS-32 & -0.2 & -0.1 \\
\hline $\mathrm{HCl}-17$ & -3.8 & -1.3 & $\mathrm{CS}-22$ & -0.2 & -0.1 \\
\hline HF-19 & -3.2 & -1.0 & CP-21 & -0.1 & -0.0 \\
\hline $\mathrm{HBr}-11$ & -3.1 & -1.0 & $\mathrm{PN}-14$ & 0.1 & 0.1 \\
\hline $\mathrm{HBr}-19$ & -3.1 & -1.0 & HNC3-14222 & -0.1 & -0.1 \\
\hline CH-21 & -2.6 & -0.8 & N2O-446 & -0.1 & -0.0 \\
\hline NH-41 & -2.5 & -0.8 & $\mathrm{O} 2-68$ & 0.1 & 0.0 \\
\hline C2S-322 & 1.9 & 0.6 & $\mathrm{C} 3 \mathrm{~N}-2224$ & -0.1 & -0.0 \\
\hline C2S-224 & 1.8 & 0.6 & HC2NC-12242 & -0.1 & -0.0 \\
\hline C2S-232 & 1.8 & 0.6 & HCCCN-12225 & -0.1 & -0.0 \\
\hline C2S-222 & 1.8 & 0.6 & HCCCN-12234 & -0.1 & -0.0 \\
\hline HF-29 & -1.6 & -0.5 & OCS-624 & -0.1 & 1.6 \\
\hline $\mathrm{OH}-81$ & 1.6 & 1.4 & OCS-622 & -0.1 & -0.1 \\
\hline OH-61 & 1.5 & 1.4 & $\mathrm{~N} 2 \mathrm{O}-456$ & -0.1 & -0.0 \\
\hline НСР-221 & -1.1 & -0.8 & $\mathrm{CO} 2-627$ & -0.1 & -0.0 \\
\hline BrO-16 & 1.1 & 0.8 & O2-67 & 0.0 & 0.0 \\
\hline BrO-96 & 1.1 & 0.8 & HCCCN-22224 & -0.0 & -0.0 \\
\hline $\mathrm{HCl}-27$ & -0.8 & -0.2 & HCCCN-13224 & -0.0 & -0.0 \\
\hline $\mathrm{HCl}-25$ & -0.8 & -0.2 & HCCCN-12324 & -0.0 & -0.0 \\
\hline НCР-121 & -0.5 & -0.4 & OCS-822 & -0.0 & -0.1 \\
\hline $\mathrm{NO}+-46$ & -0.3 & -0.1 & OCS-632 & -0.0 & -0.0 \\
\hline HNC-143 & -0.3 & -0.1 & $\mathrm{~N} 2 \mathrm{O}-448$ & -0.0 & -0.0 \\
\hline $\mathrm{HCN}-134$ & -0.3 & -0.1 & $\mathrm{~N} 2 \mathrm{O}-546$ & -0.0 & -0.0 \\
\hline $\mathrm{CN}-34$ & -0.3 & -0.1 & $\mathrm{CO} 2-628$ & -0.0 & -0.0 \\
\hline $\mathrm{CN}-24$ & -0.3 & -0.1 & $\mathrm{C} 3 \mathrm{O}-3226$ & -0.0 & 0.0 \\
\hline $\mathrm{CO}-27$ & -0.3 & -0.1 & HCCCN-12224 & -0.0 & -0.0 \\
\hline $\mathrm{CO}-28$ & -0.3 & -0.1 & $\mathrm{C} 3 \mathrm{O}-2228$ & -0.0 & -0.0 \\
\hline $\mathrm{CO}-36$ & -0.3 & -0.1 & $\mathrm{C} 3 \mathrm{O}-2236$ & -0.0 & 0.0 \\
\hline $\mathrm{CO}-26$ & -0.3 & -0.1 & C3O-2326 & -0.0 & -0.0 \\
\hline
\end{tabular}




\section{ARTICLE IN PRESS}

12 C.L. Verdes et al. / Journal of Quantitative Spectroscopy \& Radiative Transfer III (III) III-II

Table 2 (continued)

\begin{tabular}{|c|c|c|c|c|c|}
\hline Molecule & $\Delta_{150 \mathrm{~K}}(\%)$ & $\Delta_{225 \mathrm{~K}}(\%)$ & Molecule & $\Delta_{150 \mathrm{~K}}(\%)$ & $\Delta_{225 \mathrm{~K}}(\%)$ \\
\hline \multicolumn{6}{|c|}{ Non-linear molecules with three atoms } \\
\hline O3-666 & 4.8 & 3.5 & HOBr-161 & 0.1 & 0.1 \\
\hline OClO-656 & -3.8 & -3.7 & $\mathrm{SO} 2-636$ & 0.1 & 0.1 \\
\hline OClO-676 & -3.3 & -2.5 & $\mathrm{SO} 2-646$ & 0.1 & 0.1 \\
\hline H2O-171 & -1.2 & -0.3 & OBrO-696 & -0.1 & -0.0 \\
\hline H2O-161 & -1.1 & -0.3 & HCO-126 & 0.1 & 0.0 \\
\hline $\mathrm{H} 2 \mathrm{O}-181$ & -1.1 & -0.3 & HOBr-169 & 0.1 & 0.1 \\
\hline $\mathrm{H} 2 \mathrm{O}-162$ & -0.7 & -0.2 & $\mathrm{SO} 2-628$ & 0.1 & 0.1 \\
\hline H2S-122 & -0.7 & -0.4 & SO2-626 & 0.1 & 0.1 \\
\hline H2O-182 & -0.7 & -0.2 & HOCl-167 & 0.1 & 0.0 \\
\hline H2S-121 & -0.5 & -0.1 & HOCl-165 & 0.1 & 0.0 \\
\hline $\mathrm{H} 2 \mathrm{O}-262$ & -0.5 & -0.1 & O3-667 & 0.1 & 0.0 \\
\hline HNO-246 & -0.4 & -0.3 & O3-686 & -0.1 & -0.0 \\
\hline HNO-146 & -0.3 & -0.2 & O3-668 & 0.0 & -0.0 \\
\hline NO2-646 & 0.2 & 0.1 & HO2-166 & -0.0 & -0.0 \\
\hline PO2-166 & -0.1 & -0.3 & O3-676 & 0.0 & 0.0 \\
\hline OBrO-616 & -0.1 & 0.2 & & & \\
\hline \multicolumn{6}{|c|}{ Non-linear molecules with four atoms } \\
\hline $\mathrm{CH} 3 \mathrm{CN}-211124$ & 27.4 & 13.0 & CH3C2H-3111221 & -0.1 & 0.0 \\
\hline ClONO2-5646 & 19.7 & 7.2 & $\mathrm{CH} 3 \mathrm{C} 2 \mathrm{H}-2111231$ & -0.1 & 0.0 \\
\hline $\mathrm{ClONO} 2-7646$ & 19.7 & 7.2 & $\mathrm{CH} 3 \mathrm{CN}-211224$ & 0.0 & 0.0 \\
\hline HOONO2-1646 & -14.8 & -10.0 & $\mathrm{CH} 3 \mathrm{CN}-211125$ & 0.0 & 0.0 \\
\hline NH2CN-41124 & 10.4 & 3.6 & H2SO4-126 & 0.0 & 0.0 \\
\hline CH2CO-21126 & 6.3 & 1.1 & CH3CN-211134 & 0.0 & 0.0 \\
\hline СH3C2H-2112221 & -4.1 & 0.1 & CH3CN-311124 & 0.0 & 0.0 \\
\hline HCOOH-2261 & 2.6 & -0.0 & НСOOH-1361 & 0.0 & -13.4 \\
\hline СH3C2H-2111222 & -1.0 & -0.0 & CH2NH-21151 & -0.0 & -0.0 \\
\hline CH2CO-21226 & 0.8 & 0.0 & CH2NH-31141 & -0.0 & -0.0 \\
\hline CH4-212 & -0.4 & -17.1 & НCOOH-1262 & -0.0 & -0.0 \\
\hline CH2NH-21142 & -0.1 & -0.0 & НCOOH-1261 & -0.0 & -0.0 \\
\hline CH2NH-21141 & -0.1 & 0.7 & $\mathrm{CH} 3 \mathrm{Cl}-217$ & -0.0 & -0.1 \\
\hline СН3C2H-2111321 & -0.1 & 0.0 & $\mathrm{CH} 3 \mathrm{Cl}-215$ & -0.0 & 0.0 \\
\hline CH3C2H-2111221 & -0.1 & 0.0 & HNO3-146 & -0.0 & -0.0 \\
\hline \multicolumn{6}{|c|}{ Non-linear molecules with five atoms } \\
\hline CH3CN-211124 & 27 & 13 & $\mathrm{CH} 2 \mathrm{CO}-21126$ & 6 & 1 \\
\hline ClONO2-5646 & 20 & 7 & $\mathrm{CH} 3 \mathrm{C} 2 \mathrm{H}-2112221$ & -4 & 0 \\
\hline ClONO2-7646 & 20 & 7 & HCOOH-2261 & 3 & -0 \\
\hline HOONO2-1646 & -15 & -10 & $\mathrm{CH} 3 \mathrm{C} 2 \mathrm{H}-2111222$ & -1 & -0 \\
\hline NH2CN-41124 & 10 & 4 & & & \\
\hline
\end{tabular}

The notation for the molecular species isotopes generally follows the HITRAN convention, i.e., each digit represents the last digit of the sum of the neutrons and protons of the individual atoms. No vibrational correction to the JPL partition function is applied. 


\section{ARTICLE IN PRESS}

C.L. Verdes et al. / Journal of Quantitative Spectroscopy \& Radiative Transfer II (II) II- II

Table 3

Deviation of the vibrationally corrected JPL partition function ratios $\left(R(T)=Q\left(T_{0}\right) / Q(T)\right)$ from the HITRAN partition function ratios, for a reference temperature $T_{0}=300 \mathrm{~K}$, and $T$ set to 150 and $225 \mathrm{~K}$.

\begin{tabular}{|c|c|c|c|c|c|}
\hline Molecule & $\Delta_{150 \mathrm{~K}}(\%)$ & $\Delta_{225 \mathrm{~K}}(\%)$ & Molecule & $\Delta_{150 \mathrm{~K}}(\%)$ & $\Delta_{225 \mathrm{~K}}(\%)$ \\
\hline ClONO2-7646 & -23.4 & -12.5 & OCS-624 & -0.3 & 1.5 \\
\hline ClONO2-5646 & -23.4 & -12.5 & H2S-121 & 0.3 & 0.1 \\
\hline $\mathrm{HC} 1-15$ & -2.3 & -0.8 & HCOOH-126 & -0.3 & -0.1 \\
\hline HC1-17 & -2.3 & -0.8 & $\mathrm{CO} 2-627$ & -0.3 & -0.1 \\
\hline HOBr-161 & -2.2 & -1.3 & COF2-269 & -0.2 & -0.1 \\
\hline HOBr-169 & -2.2 & -1.3 & $\mathrm{~N} 2 \mathrm{O}-446$ & -0.2 & -0.1 \\
\hline $\mathrm{HBr}-11$ & -1.9 & -0.6 & HNO3-146 & -0.2 & -0.1 \\
\hline HBr-19 & -1.9 & -0.6 & OCS-622 & -0.2 & -0.1 \\
\hline OCS-632 & -1.3 & -0.7 & $\mathrm{HCN}-124$ & -0.2 & -0.1 \\
\hline H2O-162 & -1.3 & -0.4 & NO2-646 & 0.2 & 0.1 \\
\hline PH3-1111 & -1.3 & -0.9 & O3-666 & -0.1 & -0.1 \\
\hline H2O2-1661 & -1.2 & -0.9 & HO2-166 & 0.1 & 0.1 \\
\hline H2O-171 & -1.2 & -0.4 & $\mathrm{CO}-36$ & -0.1 & -0.0 \\
\hline $\mathrm{ClO}-76$ & 1.1 & 1.1 & CO-28 & -0.1 & -0.0 \\
\hline $\mathrm{ClO}-56$ & 1.1 & 1.0 & $\mathrm{CO}-27$ & -0.1 & -0.0 \\
\hline OCS-822 & -1.0 & -0.6 & O2-66 & 0.1 & 0.0 \\
\hline H2O-181 & -1.0 & -0.3 & $\mathrm{CO}-26$ & -0.1 & -0.0 \\
\hline N2O-456 & -0.9 & -0.5 & CH3C1-217 & -0.1 & -0.1 \\
\hline NH3-5111 & -0.8 & -17.0 & $\mathrm{CH} 3 \mathrm{Cl}-215$ & -0.1 & -0.0 \\
\hline O2-67 & -0.7 & -0.2 & $\mathrm{H} 2 \mathrm{O}-182$ & -0.1 & -0.1 \\
\hline O2-68 & -0.7 & -0.2 & H2CO-1126 & -0.1 & -0.0 \\
\hline NH3-4111 & -0.6 & -0.5 & $\mathrm{NO}+-46$ & -0.0 & -0.0 \\
\hline O3-686 & -0.6 & -0.4 & SO2-646 & 0.0 & 0.0 \\
\hline O3-668 & -0.6 & -0.4 & $\mathrm{OH}-81$ & 0.0 & -0.0 \\
\hline N2O-448 & -0.4 & -0.3 & $\mathrm{CH} 4-212$ & -0.0 & -17.0 \\
\hline $\mathrm{HCN}-125$ & -0.4 & -0.3 & H2CO-1128 & 0.0 & -0.0 \\
\hline NO-46 & -0.4 & -0.1 & HF-19 & -0.0 & 0.0 \\
\hline H2CO-1136 & -0.4 & -0.5 & H2O-161 & -0.0 & -0.0 \\
\hline O3-676 & -0.4 & -0.2 & $\mathrm{SO} 2-626$ & -0.0 & 0.0 \\
\hline O3-667 & -0.4 & -0.2 & OH-61 & 0.0 & -0.0 \\
\hline N2O-546 & -0.4 & -0.2 & HOC1-165 & 0.0 & -0.0 \\
\hline HCN-134 & -0.3 & -0.2 & HOC1-167 & 0.0 & -0.0 \\
\hline $\mathrm{CO} 2-628$ & -0.3 & -0.2 & OH-62 & -0.0 & -0.0 \\
\hline
\end{tabular}

The notation for the molecular species isotopes generally follows the HITRAN convention, i.e., each digit represents the last digit of the sum of the neutrons and protons of the individual atoms.

\section{Impact on the retrieval}

\subsection{Instrumental and retrieval set-up}

In order to establish the sensitivity of the retrieval to the partition function data, retrieval simulations have been carried out. The instrumental characteristics specific to the state-of-the-art MASTER instrument (Millimetre-wave Acquisitions for Stratosphere/Troposphere Exchange Research), studied 


\section{ARTICLE IN PRESS}

14
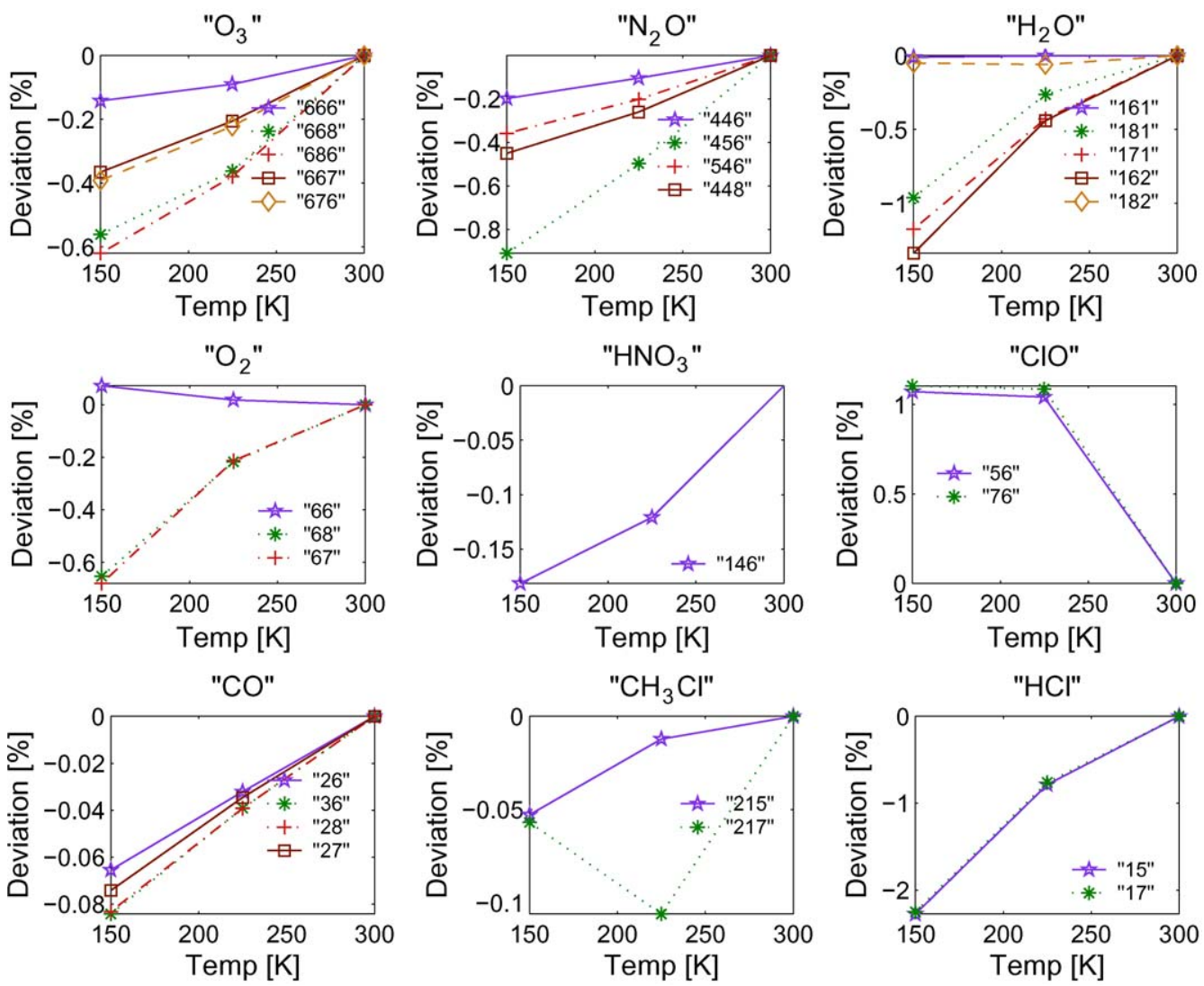

Fig. 3. Relative deviation of the JPL partition function ratios $\left(Q\left(T_{0}\right) Q(T)\right)$ from the HITRAN partition function ratios. Displayed are the ratios of the two partition function at three temperatures $(150,225$, and $300 \mathrm{~K})$. The reference temperature is set to $300 \mathrm{~K}$ (thus, the error at this temperature is 0 ). Each plot shows the data for different isotopes of a particular molecular species found both in the HITRAN and JPL database. The notation for the molecular species isotopes generally follows the HITRAN convention, i.e., each digit represents the last digit of the sum of the neutrons and protons of the individual atoms.

by the European Space Agency, are used. The considered instrumental requirements have been investigated in depth and optimized in a series of studies [e.g., [23-26]]. The instrument is an SSB heterodyne spectrometer observing thermal emissions from the Earth's atmosphere in a number of millimeter and sub-millimeter wave bands. Its principal objective is to provide innovative global measurements of the atmospheric composition in order to improve the knowledge of the dynamics, radiation budget, and chemistry of the upper troposphere and lower stratosphere. The instrument will be configured to scan the atmosphere in limb from 0 to $50 \mathrm{~km}$ in the orbit plane $(\approx 820 \mathrm{~km}$ orbit altitude), with an integration time $\tau=0.3 \mathrm{~s}$, corresponding to a sampling in tangent altitude steps of $1 \mathrm{~km}$. Global measurements of thermal emission induced by rotational transitions of atmospheric molecules will be performed in five spectral bands within the frequency range of 294-626.5 GHz. The instrument is characterized by a system noise temperature $T_{\mathrm{sys}} \approx 6000 \mathrm{~K}$. Spectral measurements will be performed with a resolution of $\Delta v=50 \mathrm{MHz}$ over the complete frequency range. The 
main target species are $\mathrm{O}_{3}$ (in Bands $\mathrm{B}, \mathrm{C}, \mathrm{E}$, and $\mathrm{F}$ ), $\mathrm{HNO}_{3}$ (in Bands $\mathrm{B}$ and $\mathrm{C}$ ), $\mathrm{N}_{2} \mathrm{O}$ (in Bands $\mathrm{B}$ and $\mathrm{E}$ ), $\mathrm{CO}$ (in Band $\mathrm{D}$ ), $\mathrm{ClO}$ (in Band $\mathrm{E}$ ), $\mathrm{BrO}$ (in Bands $\mathrm{D}$ and $\mathrm{E}$ ), $\mathrm{H}_{2} \mathrm{O}$ (in Bands $\mathrm{C}$ and $\mathrm{E}$ ), and $\mathrm{HCl}$ (in Band $\mathrm{F}$ ).

The used spectral database is the MYTRAN catalog [27,28] developed in the context of the MASTER instrument study. The MYTRAN catalogue is mainly based on the HITRAN database but with some additional lines and species (e.g., BrO) from JPL. The absorption spectra for each species included in the forward calculation, and the total absorption in each spectral band are shown in Fig. 4.

For an atmospheric scenario, specified through the molecular species VMR, and the temperature/pressure profiles (Fig. 5), the simultaneous retrievals of molecular species VMR profiles, temperature profile, and instrumental pointing offset ${ }^{2}$ were performed using simulated measurements of an entire elevation scan cycle $(0-50 \mathrm{~km})$. The used forward model is atmospheric radiative transfer simulator (ARTS) [29]. The retrieval is performed by using Qpack [30], which is a Matlab environment to perform OEM inversions and to produce sets of spectra to test the inversions, using ARTS as calculating engine. The molecular species profiles are retrieved in relative units of VMR, over the altitude range of $0-60 \mathrm{~km}$. The vertical retrieval grid is specified in logarithmic pressure units and it corresponds to a spacing of approximately $2 \mathrm{~km}$ in tangent altitude. The a priori error is set to $100 \%$ throughout, and no correlation between the retrieval levels is considered (off-diagonal elements of $\mathrm{S}_{\mathrm{a}}$ are set to 0 ). The atmospheric temperature profile is retrieved on a vertical grid given as the logarithm of the atmospheric pressure corresponding to a vertical spacing of about $3 \mathrm{~km}$. A variability of the atmospheric temperature (a priori error) of $5 \mathrm{~K}$ is assumed, and no correlation between the retrieval levels are considered (a diagonal $S_{a}$ matrix). Only the thermal noise is included in the measurement noise, and no interchannel correlations are considered, i.e., a diagonal $\mathrm{S}_{\varepsilon}$ with the diagonal elements set to $\left(T_{\text {sys }} / \sqrt{\Delta v \tau}\right)^{2}$ (the so-called radiometric formula).

The reference measurement is simulated by assuming the partition functions as quoted in HITRAN. The 'perturbed' measurement is simulated by assuming the vibrationally corrected JPL partition functions, and the error in the retrieval is calculated by linear mapping, i.e., using Eq. (12). For the case when only one data set provides the partition function for a particular molecular species, then the reference and 'perturbed' measurement are generated from this data set. This applies to the BrO molecule, where only JPL provides the partition function data. The reference and the 'perturbed' measurement are simulated with the same partition function for this molecule; thus, the investigated retrieval error of $\mathrm{BrO}$ is only caused by different partition function data of other molecules which have spectral features in the vicinity of the $\mathrm{BrO}$ lines.

\subsection{Results and discussions}

The assumption of the JPL partition functions (to which the vibrational correction has been applied) instead of the HITRAN partition functions generates a deviation in the measurement, $\Delta_{\mathrm{y}}$, as large as $0.4 \mathrm{~K}$ (Fig. 6). As expected, this occurs mainly in the spectral range where emission lines of molecular species for which the two partition function data sets deviate the most, are found, e.g., around $344.3 \mathrm{GHz}$ in Band $\mathrm{D}$ where an $\mathrm{HNO}_{3}$ line cluster is found (Fig. 6, left plot), or in Band E (Fig. 6, right plot), but this time mainly due to the difference in the two partition function data

\footnotetext{
${ }^{2}$ Pointing offset means that all the altitudes are higher or lower.
} 


\section{ARTICLE IN PRESS}
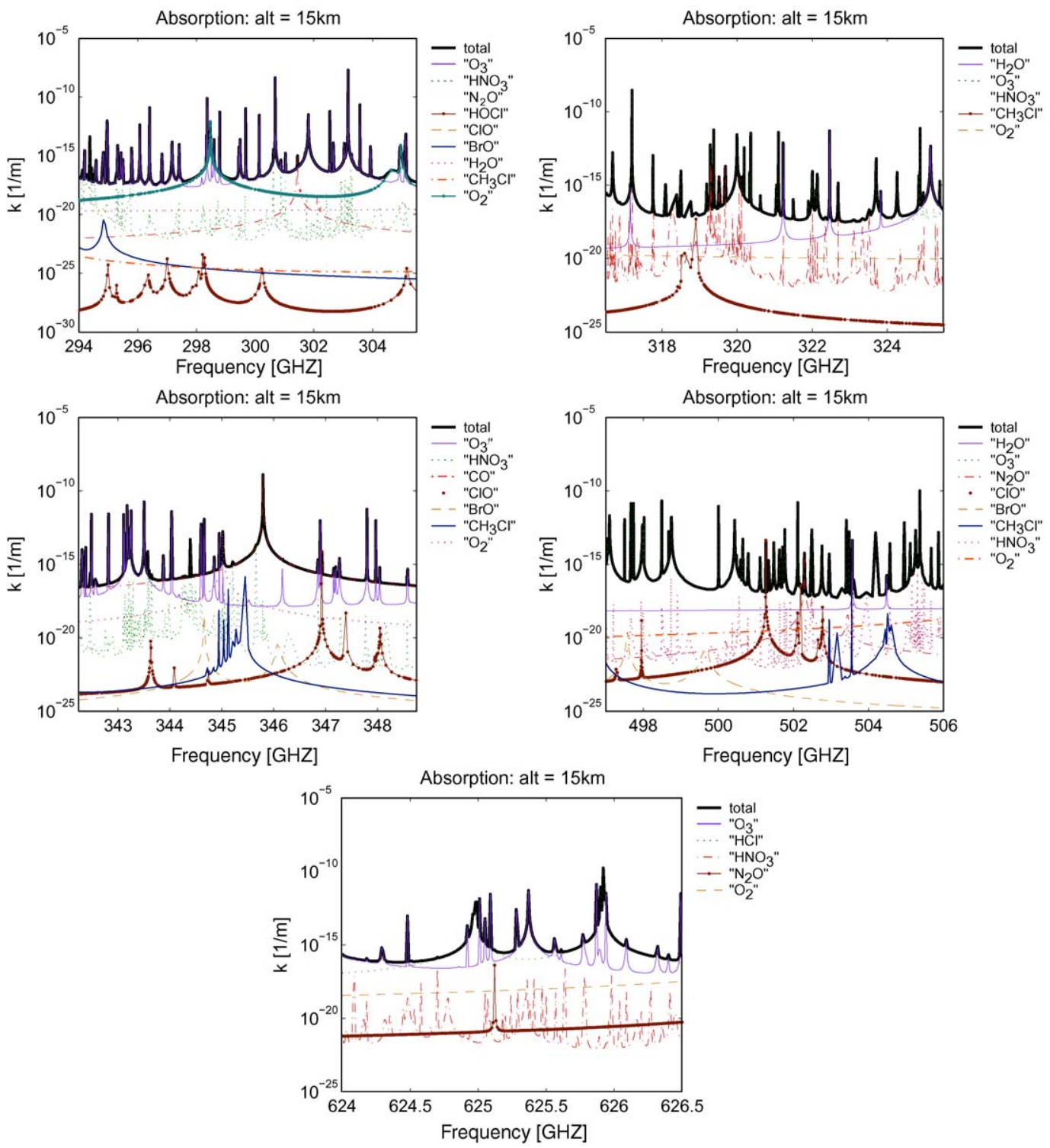

Fig. 4. MASTER spectral bands. Displayed are the species absorption and total absorption spectra.

sets for $\mathrm{O}_{3}$. Since the deviation in the partition function is mostly negative, the deviation in the measurement $\Delta_{\mathrm{y}}$ is also negative. A close look at Fig. 6, right plot, shows a slightly positive $\Delta_{\mathrm{y}}$ around $501.2 \mathrm{GHz}$ where a $\mathrm{ClO}$ line is located. This is a consequence of the higher JPL partition function ratios for $\mathrm{ClO}$ compared to the HITRAN ones (see Fig. 3 ).

By performing an error analysis, an error of about $0.3 \%$ on the retrieved $\mathrm{O}_{3}$ in Bands $\mathrm{B}, \mathrm{C}$ and F (Fig. 7) is found. This has a similar magnitude as the deviations of the JPL partition function ratios from the HITRAN ones (Fig. 3). A deviation in the partition function is directly translated 


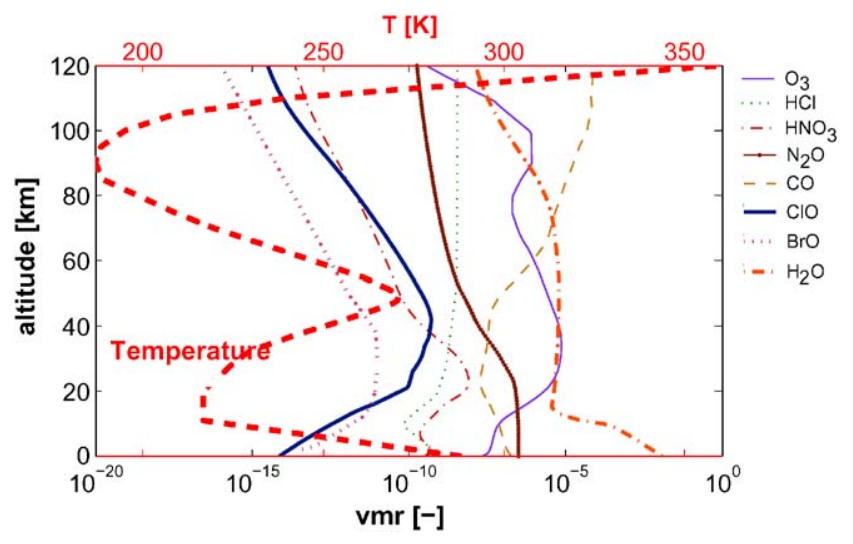

Fig. 5. Molecular species VMR profiles and temperature profile used in calculation.
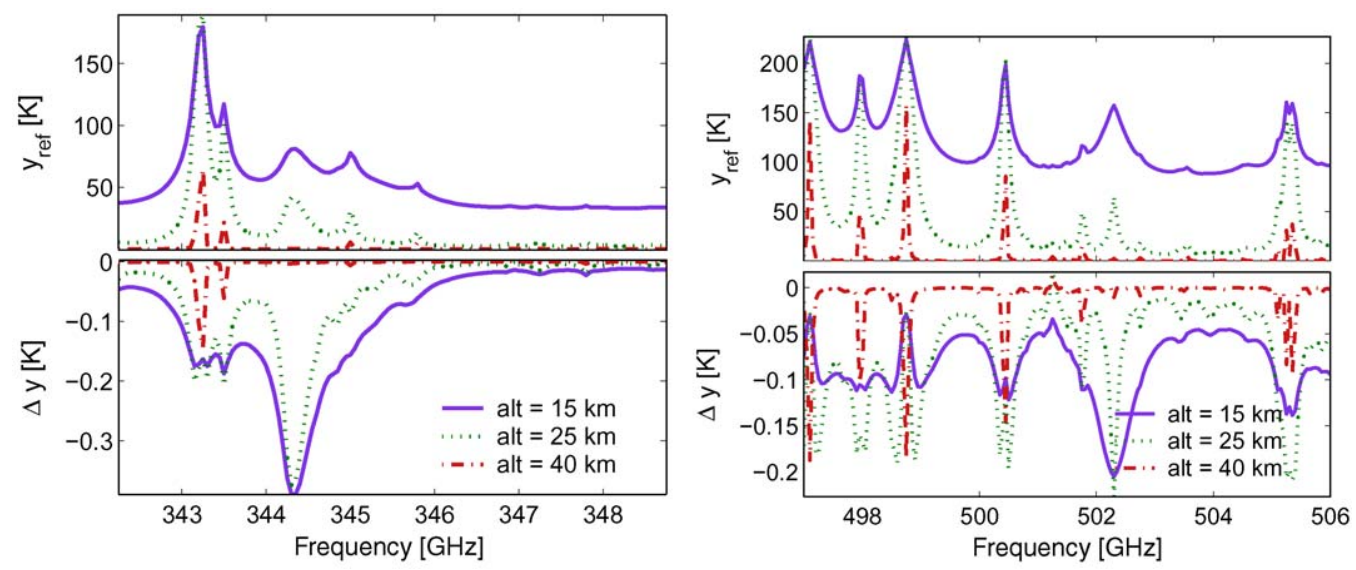

Fig. 6. Simulated measurement (upper plots), and the difference in the measurement (lower plots) by assuming JPL partition functions instead HITRAN partition functions, for three altitudes $(15,25$, and $40 \mathrm{~km})$ and for two spectral ranges (Bands D and E).

into a change of the line strength which is directly translated into a retrieval error, due to the linear relation between the absorption coefficient and the line strength (Eq. (3)). The error on the retrieved $\mathrm{N}_{2} \mathrm{O}$ reaches a value of $0.4 \%$ (see Fig. 8, left plot), i.e., the same order of magnitude as the found deviation in partition function ratios (see Fig. 1). Regarding the $\mathrm{HNO}_{3}$ retrieval, the JPL partition function ratios have slightly larger deviations from the HITRAN ones, and therefore the retrieval error is also slightly larger. This reaches a value larger than $1 \%$ in the altitude range where a good retrieval precision is achieved (see Fig. 8, middle plot). The error on the $\mathrm{ClO}$ retrieval is only remarkable at altitudes around $20 \mathrm{~km}$ (Fig. 8, right plot), which is caused by the deviation, mainly at low temperatures (see Fig. 3), of the JPL partition function ratios from the HITRAN ones. By looking at the temperature profiles (Fig. 5), one sees that the lowest temperatures are reached at altitudes between 15 and about $20 \mathrm{~km}$, explaining the found behavior. 


\section{ARTICLE IN PRESS}

18

C.L. Verdes et al. / Journal of Quantitative Spectroscopy \& Radiative Transfer II (III) II-II
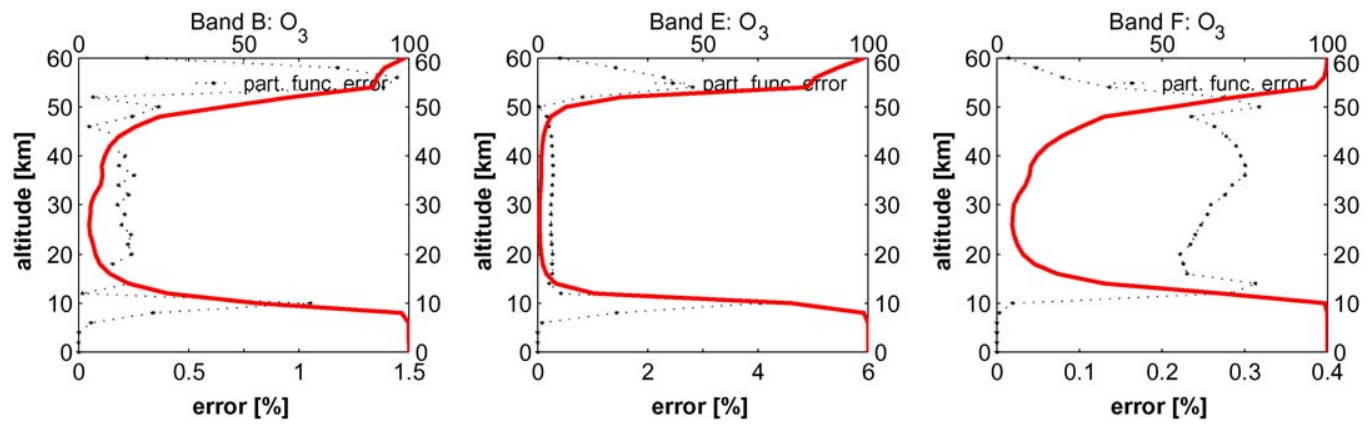

Fig. 7. Error on the retrieved $\mathrm{O}_{3}$ in Band $\mathrm{B}$ (left), in Band $\mathrm{E}$ (middle), and in Band $\mathrm{F}$ (right). The retrieval precision is also displayed in each plot. For the sake of clarity two $x$-axis are used: the bottom $x$-axis refers to the error due to the differences in the partition function (displayed with dotted line), while the top $x$-axis refers to the retrieval precision (displayed with solid line).
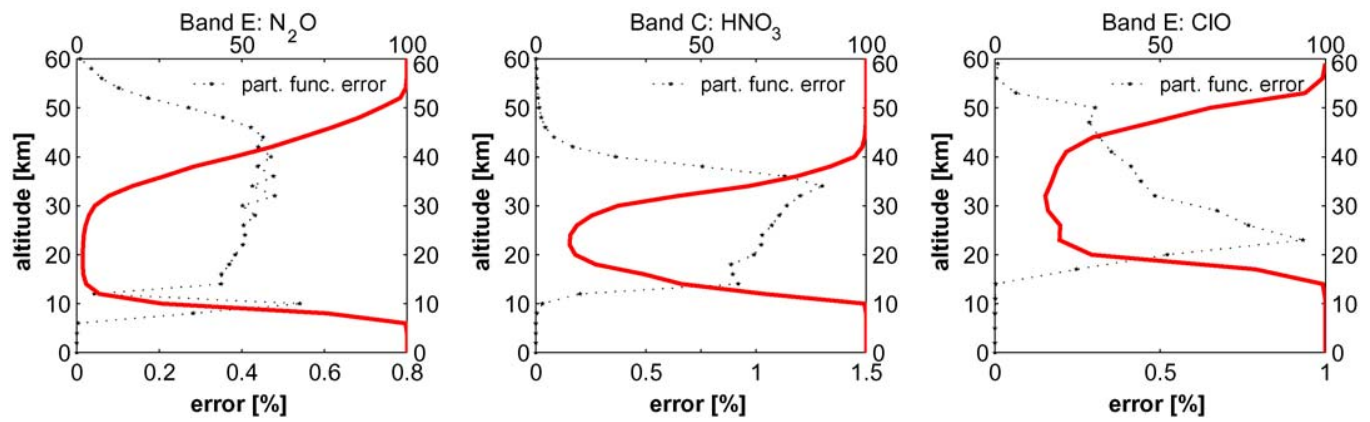

Fig. 8. Error on retrieved $\mathrm{N}_{2} \mathrm{O}$ in Band $\mathrm{E}$ (left) and $\mathrm{HNO}_{3}$ in Band $\mathrm{C}$ (middle), and $\mathrm{ClO}$ in Band $\mathrm{E}$ (right). The retrieval precision is also displayed in each plot. For the sake of clarity two $x$-axis are used: the bottom $x$-axis refers to the error due to the differences in the partition function (displayed with dotted line), while the top $x$-axis refers to the retrieval precision (displayed with solid line).

It is interesting to see that the error on the retrieved $\mathrm{BrO}$ is rather large (see Fig. 9), despite the fact that the same data for the partition function has been used (only JPL provides the partition function for this species) to simulate the reference and 'perturbed' measurement. The error is slightly larger for the retrieved BrO in Band E. By looking at the species absorption spectra (Fig. 4), one sees that the strongest $\mathrm{BrO}$ lines are superimposed on strong lines assigned to other molecular species, and therefore the information on $\mathrm{BrO}$ cannot be well separated. Therefore, wrong partition functions of the other molecular species are partially turned into systematic error on the retrieved $\mathrm{BrO}$. The error on $\mathrm{HCl}$ in Band $\mathrm{F}$ has a maximum of about $0.9 \%$, thus, again similar to the deviation in the partition function ratios (Fig. 3).

All presented results refer to the major isotopes; thus, they are unaffected by the used approximation for the vibrational corrections of minor isotopes (using the vibrational modes of the main isotopes). 

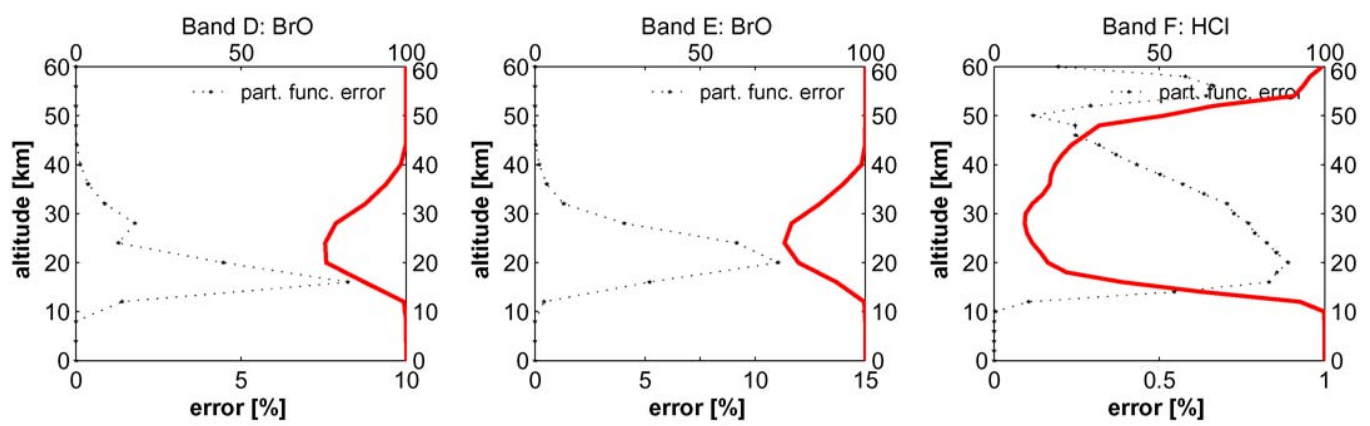

Fig. 9. Error on retrieved $\mathrm{BrO}$ in Band $\mathrm{D}$ (left), and Band $\mathrm{E}$ (middle), and retrieved $\mathrm{HCl}$ in Band $\mathrm{F}$ (right). The retrieval precision is also displayed in each plot. For the sake of clarity two $x$-axis are used: the bottom $x$-axis refers to the error due to the differences in the partition function (displayed with dotted line), while the top $x$-axis refers to the retrieval precision (displayed with solid line).
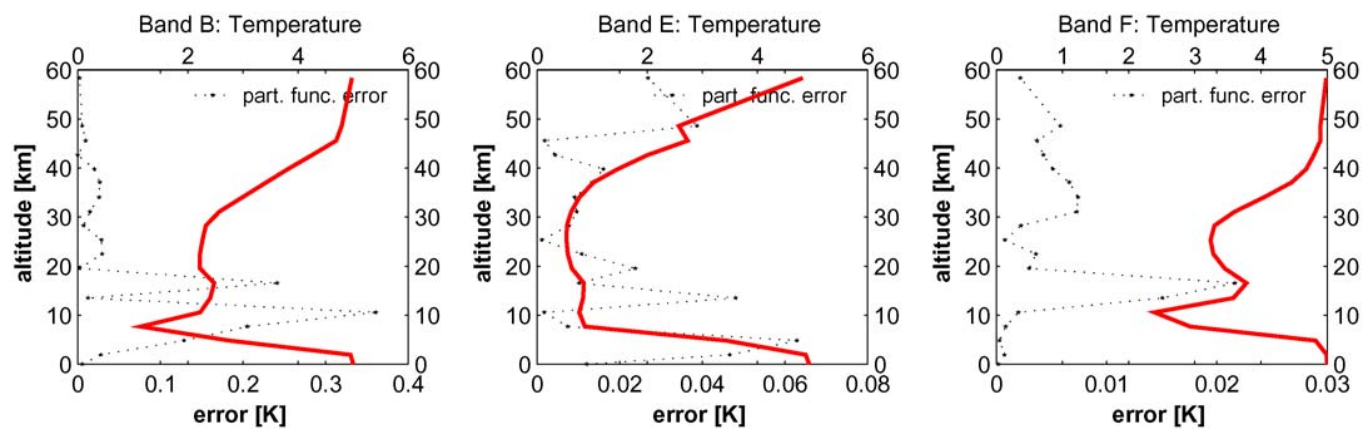

Fig. 10. Error on the retrieved atmospheric temperature profile in Band B (left), in Band E (middle), and in Band F (right). The retrieval precision is also displayed in each plot. For the sake of clarity two $x$-axis are used: the bottom $x$-axis refers to the error due to the differences in the partition function (displayed with dotted line), while the top axis refers to the retrieval precision (displayed with solid line).

Regarding the temperature retrieval, one sees that the error caused by the different partition functions could reach a value of about $0.4 \mathrm{~K}$ at lower stratospheric altitudes (Fig. 10). This is expected as generally the differences in the partition function ratios are increasing with decreasing temperature (see Fig. 3 and Table 3). Fig. 4 shows that the lower temperatures are reached at lower stratospheric altitudes, explaining the error which appears at this altitudes. The error in case of Band B is larger, due to the fact that the information on the temperature are mainly taken from the $\mathrm{O}_{2}$ minor isotope ('67') line, while in the other displayed bands (Bands E and F) the information are mainly extracted from the $\mathrm{O}_{3}$ lines. The deviations in the two partition function ratio data sets for the minor isotopes $\mathrm{O}_{2}$ are about $0.6 \%$ at low temperatures, larger compared to the $\mathrm{O}_{3}$ ones (see Fig. 4).

\section{Conclusion}

The purpose of this paper was to compare different existing partition function data sets. The investigation focused on the HITRAN and JPL partition function ratio, $R(T)=Q(T) / Q\left(T_{0}\right)$, as this is the interested quantity for our purpose. In a first step, the spread of the partition function 
ratios given in the two data sets from a simple approximation value $\left(R_{\text {simple }}\right)$ given by theory was investigated. We found that the HITRAN partition function ratios are usually higher than the values quoted by the simple approximation. This is well understood as the approximation refers to the rotational partition function while the HITRAN provides the total partition function. The highest deviation is found for $\mathrm{ClO}(16 \%$, explained by the fact that this molecule has a high vibrational mode), but also for other molecules (usually molecules with a more complicated structure) such as $\mathrm{SF}_{6}(188 \%$ at $150 \mathrm{~K}), \mathrm{ClONO}_{2}(158 \%$ at $150 \mathrm{~K})$ (see Table 1$)$. The JPL partition functions (which refers only to the rotational part) are much closer to the simple approximation values. The highest deviations are also found for some molecules with a high number of atoms such as $\mathrm{CH}_{3} \mathrm{CN}(27 \%$ at $150 \mathrm{~K})$, and $\mathrm{ClONO}_{2}(19 \%$ at $150 \mathrm{~K})$, but also for the linear molecules $\mathrm{NS}(20 \%)$, NO $(18 \%)$, $\mathrm{ClO}(18 \%)$.

Comparing directly HITRAN and JPL partition function ratios we found that, with some exceptions, the two data sets are in good agreement, if a vibrational correction is applied to the JPL partition functions. Only for 16 molecules (out of 66 considered molecules), the deviations in the two data sets are larger than $1 \%$. The largest discrepancy appears for $\mathrm{ClONO}_{2}(23 \%$ at $150 \mathrm{~K})$. Some deviations, much smaller (around $2 \%$, or less), are found, e.g., for $\mathrm{HCl}, \mathrm{HOBr}$, and $\mathrm{HBr}$. The best agreement is found, e.g., for $\mathrm{OH}, \mathrm{HOCl}, \mathrm{H}_{2} \mathrm{O}$ (main isotope), and $\mathrm{SO}_{2}$.

Retrieval simulations (employing OEM) and a basic error analysis (using linear mapping method) show that an uncertainty in partition function can lead to a retrieval error of the same magnitude as the uncertainty itself. The MASTER instrument is chosen as a state-of-the-art instrument. We find that, for the case of the molecular species with strong signatures, an uncertainty in the partition function ratio is directly translated into a retrieval error. This is the case, e.g., for $\mathrm{O}_{3}$ for which the deviation of about $0.3 \%$ of the JPL partition function ratio from the HITRAN one generates an error of $0.3 \%$ on the retrieved $\mathrm{O}_{3}$, in the altitude range where a good retrieval precision is achieved (15$45 \mathrm{~km})$. An uncertainty in the partition function of molecular species with strong signatures can have a high impact on the quality of weak species retrieval. This is the case for $\mathrm{BrO}$, although the same partition function data was used to simulate both the reference and the 'perturbed' measurement, the error due to the uncertainties of the partition function of other molecular species generate an error of about $20 \%$ on the retrieved $\mathrm{BrO}$.

In conclusion, one has to point out that care should be taken when the partition function data are used. For the considered instrumental set-up, the errors are not so dramatical for a particular profile, a consequence of the fact that no molecular species with very different partition functions are involved. However, one should keep in mind that the error in the partition function propagates almost linearly into the retrieval of the molecular species in concern. Thus, the retrieval error would be much critical for molecular species having high uncertainties in the partition function (such as $\mathrm{ClONO}_{2}$ ). Also the introduced error is a systematic one, small systematic errors in $\mathrm{O}_{3}$, as found here, are important for trend analysis over longer time spans.

\section{Acknowledgements}

The authors acknowledge the contribution of all that have helped in this study. A special credit is due to Robert R. Gamache from the University of Massachusetts Lowell, for providing us with the program to calculate the total internal partition function associated with HITRAN database. The 
authors want to thank Franz Schreier from Deutschen zentrum für huft - und Raumfahrt (DLR) for providing with the data for the vibrational correction of the JPL partition function. We further want to thank the HITRAN and JPL team. This work was funded by the German Federal Ministry of Education and Research (BMBF), within the DLR project SMILES, Grant 50EE9815. It was co-funded by the ESA study 'Characterization of Millimetre-Wave Spectroscopic Signatures', ESTEC Contract No. 16377/02/NL/FF. It also is a contribution to COST Action 723 'Data Exploitation and Modeling for the Upper Troposphere and Lower Stratosphere'.

\section{References}

[1] Chandrasekhar S. Radiative transfer. New York: Dover; 1960. 393p.

[2] Buehler S. Microwave limb sounding of the stratosphere and upper troposphere. PhD thesis, University of Bremen, Berichte aus der Physik, Shaker Verlag; 1999.

[3] Verdes C. Deriving atmospheric temperature and instrumental pointing from millimeter/sub-millimeter limb sounding measurements. PhD thesis, University of Bremen, Berichte aus dem Institut für Umweltphysik, Logos Verlag, Berlin, 2002.

[4] Herzberg G. Spectra of diatomic molecules. Princeton, NJ: New York: Van Nostrand Company; 1950.

[5] Kuhn T. Atmospheric absorption models for the millimeter wave range. PhD thesis, University of Bremen, 2003.

[6] Rosenkranz PW. Absorption of microwaves by atmospheric gases. In: Janssen MA, editor. Atmospheric remote sensing by microwave radiometry. New York: Wiley; 1993. p. pp37-90.

[7] Townes CH, Schawlow AL. Microwave spectroscopy. New York: McGraw-Hill; 1955.

[8] Waters JR. Absorption and emission by atmospheric gases. In: Meeks ML, editor. Methods of experimental physics, vol. 12B. New York: Academic Press; 1976, kap. 2.3.

[9] Waters JR. Absorption and emission by atmospheric gases. Microwave Limb Sounder Technical Note, JPL, 1990 (revision 1.0).

[10] Rodgers CD. Characterization and error analysis of profiles retrieved from remote sounding measurements. J Geophys Res 1990;95:5587-95.

[11] Rodgers CD. Inverse methods for atmospheric sounding: theory and practise, Series on atmospheric, oceanic and planetary physics, vol. 2. Singapore: World Scientific; 2000.

[12] Buehler S, Eriksson P, editors. Atmospheric millimeter and sub-millimeter wave radiative transfer modeling. Aachen: Berichte aus der Physik, Shaker Verlag; 2000, ISBN 3-8265-7486-9.

[13] Fischer J, Gamache R, Goldman A, Rothman L, Perrin A. Total internal partition sums for molecular species on the hitran database. Technical Report, Department of Environmental, Earth, and Atmospheric Sciences, University of Massachusetts Lowell, 2003, in press.

[14] Goldman A, Gamache RR, Perrin A, Flaud J-M, Rinsland CP, Rothmann LS. Hitran partition functions and weighted transition-moments squared. JQSRT 2000;66:455-86.

[15] Pickett HM, Poynter RL, Cohen EA. Submillimeter, millimeter, and microwave spectral line catalogue. Jet Propulsion Laboratory, 1992.

[16] Pickett HM, Poynter RL, Cohen EA, Delitsky ML, Pearson J, Muller HSP. Submillimeter, millimeter, and microwave spectral line catalogue. JQSRT 1998;60:883-90.

[17] Pickett HM, Poynter RL, Cohen EA. Submillimeter, millimeter, and microwave spectral line catalogue. Jet Propulsion Laboratory; 2001.

[18] Rothman LS, et al. The HITRAN molecular spectroscopic database: edition of 2000 including updates through 2001. JQSRT 2003;82:5-44.

[19] Norton R, Rinsland C. ATMOS data processing and science analysis methods. Appl Opt 1991;30:389-400.

[20] Smith M, Rinsland C, Fridovich B, Rao K. Intensities and collision broadening parameters from infrared spectra. In: Rao K, editor. Molecular spectroscopy: modern research, vol. III. New York: Academic press; 1985. p. pp111-248.

[21] Smith M, Rinsland C, Malathy-Devi V, Rothman L, Rao KN. Intensities and collision-broadening parameters from infrared spectra: an update. In: Rao K, Weber A, editors. Spectroscopy of the earth's atmosphere and interstellar medium. New York: Academic Press; 1992. p. pp153-260. 


\section{ARTICLE IN PRESS}

[22] Eriksson P. Microwave radiometric observations of the middle atmosphere: simulations and inversions. PhD thesis, Chalmers University of Technology, Göteborg, 1999.

[23] Buehler S, et al. The retrieval of data from sub-millimeter limb sounding. Final Report Contract No. 11979/97/NL/CN, ESTEC, Noordwijk, 1999.

[24] Reburn WJ, Siddans R, Kerridge BJ, Bühler S, von Engeln A, Eriksson P, Kuhn T, Künzi K, Verdes C. Critical assessments in millimeter-wave atmospheric limb sounding. Final Report Contract No. 13348/98/NL/GD, ESTEC, Noordwijk, 2000.

[25] Reburn WJ, et al. Study on upper troposphere/lower stratosphere sounding. Final Report Contract No. 12053/97/NL/CN, ESTEC, Noordwijk, 1998.

[26] Verdes C, Bühler S, Eriksson P, von Engeln A, Kuhn T, Künzi K, Urban J. The retrieval of data from sub-millimeter limb sounding (ccn2). Final Report Contract No. 11979/97/NL/CN, ESA/ESTEC, Noordwijk, 2000.

[27] Bauer A, et al. Study on a spectroscopic database for millimeter and submillimeter wavelengths, final Report. Final Report Contract No. 11581/95/NL/CN, ESTEC, Noordwijk, 1998.

[28] Demaison J, et al. Characterization of millimeter-wave spectroscopic signatures. Final Report, Contract No. 16377/02/NL/FF, ESTEC, Noordwijk 2004.

[29] Buehler SA, Eriksson P, Kuhn T, von Engeln A, Verdes C. Arts, atmospheric radiative transfer simulator. JQSRT, 2003, submitted for publication.

[30] Eriksson P, Jimenez C, Buehler SA. Qpack, a general tool for instrument simulation and retrieval work. JQSRT, 2003, submitted for publication. 